\title{
TEÓRICO, POLÍTICO E HISTÓRICO: UMA DISCUSSÃO SOBRE A ABORDAGEM MARXIANA DO CONCEITO DE CLASSES SOCIAIS
}

\author{
Marco Aurelio de Oliveira Leal ${ }^{1}$
}

\begin{abstract}
RESUMO: Análises desenvolvidas por Marx no século XIX ainda suscitam debates e colocam em discussão diversas categorias marxianas que não foram conceituadas em sua plenitude. Aqui trataremos de um desses conceitos, as classes sociais. Proponho uma leitura do conceito de Classes apresentado por Marx em três obras distintas e que são consideradas essenciais para a compreensão de sua teoria: $O$ Capital, $O$ Manifesto Comunista e $O 18$ de Brumário de Luís Bonaparte. Apesar de possuírem objetivos diferenciados, acredito que as três obras possuem elementos de confluência na argumentação sobre as classes sociais. Tento com isso promover um trabalho de caráter panorâmico, mas dotado de um esforço teórico com intuito de alargar as possibilidades de uso das categorias marxianas, em especial ao que concerne o estudo das classes sociais.
\end{abstract}

Palavras chave: Classe social; teoria marxiana; análise de classes.

\section{THE ORETICIAN, POLITICAL AND HISTORICAL: A DISCUSSIONON THE MARXIAN APPROACH TO THE CONCEPT OF SOCIAL CLASSES}

\begin{abstract}
Analyzes developed by Marx in the nineteenth century still give rise to debates and put into question various Marxian categories that were not conceptualized in their fullness. Here we will deal with one of these concepts, social classes. I propose a reading of the concept of Classes presented by Marx in three different works and that are considered essential for the understanding of his theory: The Capital, The Communist Manifesto and The 18 of Brumário de Luís Bonaparte. Although they have different objectives, I believe that the three works have elements of confluence in the argumentation about social classes. I try to promote a work of a panoramic character, but endowed with a theoretical effort to extend the possibilities of use of the Marxian categories, especially to what concerns the study of social classes.
\end{abstract}

Keywords: Social class; marxian theory; class analysis.

\section{IDEIAS FUNDAMENTAIS}

\footnotetext{
${ }^{1}$ É graduado em Ciências Sociais - UFPE. Atualmente é Mestrando Programa de Pós-Graduação em Sociologia da Universidade Federal de Pernambuco PPGS-UFPE, onde desenvolve pesquisas sobre a distinção das classes sociais no Brasil contemporâneo em tempos de imprevisibilidade e crise política. Possui interesses nas áreas de Pensamento Social Brasileiro, Sociologia da Cultura, Sociologia do Consumo e Teoria Sociológica.

Contato: marco.leal.cs@gmail.com
}

Programas de Pós-Graduação em Ciências Sociais e Filosofia - UNIOESTE - Rua da Faculdade 645. Toledo - PR. CEP 85.903-000 Email: revistaalamedas@gmail.com 
Antes de iniciar uma discussão acerca do conceito de classe social na teoria de Marx, que circula em suas diversas obras, acredito que seja necessário um breve comentário acerca de sua discussão sobre o que seria o sujeito-histórico. Sobre essa questão convoco uma das de suas famosas frases, esta em específico se localiza no início do 18 de Brumário de Luís Bonaparte: "Os homens fazem a sua própria história; contudo, não a fazem de livre e espontânea vontade, pois não são eles que escolhem as circunstâncias sob as quais ela é feita, mas estas lhes foram transmitidas assim como se encontraram" (MARX, 2011.p. 25).

Nesse sentido, é cabível afirmar que para Marx os coletivos humanos fazem a sua própria história, mas a estruturam a partir das próprias circunstâncias onde estes se inserem. O papel de agência dos sujeitos estará de certa forma limitado às condições materiais que estruturaram a sociedade tal qual ela está. Contudo, por serem produzidas por seres humanos, estas condições contêm em si disposições antagônicas e são mutáveis pelos seres humanos, por isso dialéticas. Nesse sentido, os sujeitos ao mesmo tempo que são atores da estrutura dada pela história são também autores da história, modificando-a dentro de certos limites.

Essa questão suscitou debates entre teóricos de base marxista até os dias de hoje, colocando as questões elencadas por Marx ainda em voga. Entretanto, refletir sobre isso na tradição marxista como um todo, ultrapassa os limites propostos neste artigo. Fiquemos então com a noção de sujeito histórico tal qual proposta por Marx, destacando com isso o que é apontado no conceito de Materialismo-Histórico ${ }^{2}$, para evidenciar como a sociedade capitalista chegou a sua estrutura de dominação evidenciada pelo autor. Na perspectiva de Giddens:

(...) a sociedade de classes é o produto de uma sequência determinada de mudanças históricas. As formas mais primitivas de sociedade humana não são os sistemas de classes. Em sociedades "tribais" - ou, nos termos de

\footnotetext{
${ }^{2} \mathrm{O}$ materialismo histórico diz respeito as condições materiais de existência dos seres humanos. Como estes se comportam no tempo e na história e como a história se modifica a partir das relações entre os sujeitos. Para Marx, em distanciamento do Idealismo Dialético de Hegel e dos jovens hegelianos, era necessário produzir uma filosofia eminentemente palpável, que possuísse como princípio fundamental a própria matéria, uma vez que compreendia toda ação humana como material, em outras palavras como concreta e transformadora da natureza. As relações serão nesse sentido, dotadas de uma realidade que se funda na matéria e possuem uma dimensão histórica.
} 
Engels, no "comunismo primitivo" - há apenas uma fraca divisão do trabalho e a propriedade existente e possuída em comum pelos membros da comunidade. A expansão da divisão do trabalho mais o aumento do nível de riqueza por ela gerado são acompanhados pelo crescimento da propriedade privada; isso envolve a criação de um produto excedente apropriado pela minoria de não-produtores que, consequentemente, se colocam numa relação de exploração frente a maioria dos produtores (GIDDENS, 1975. p. 28).

A teoria de classes em Marx nada mais é do que uma tentativa de explicar a natureza das mudanças que transformaram radicalmente a Europa, segundo Bottomore, “As classes sociais foram um elemento essencial no pensamento de Marx desde o momento em que ele descobriu (em princípios da década de 1840) o proletariado como “a ideia no próprio real"” (BOTTOMORE, 1988. p, 345).

O Capitalismo se trata, na leitura de Giddens (1975) sobre Marx, de uma fase transitória e de desordem devido à mudança do feudalismo para o industrialismo, que trouxe consigo uma nova forma genuína de sociedade. Marx não será um crítico do industrialismo, mas do industrial-capitalismo, ou seja, um crítico dos processos de exploração no mundo do trabalho no qual toda uma classe de sujeitos se vê forçada a vender a sua força de trabalho, que é o seu único bem, para sobreviver na sociedade capitalista. $\mathrm{O}$ autor advoga que o conflito entre as classes não indica um ajustamento defeituoso das funções da divisão social do trabalho, como apontaria Durkheim, mas o conflito afirma-se de maneira mais pungente com o desenvolvimento da sociedade industrial. O conflito entre as classes funciona na teoria marxiana como um elemento de caráter interno do capitalismo.

Analisemos então a abordagem de Marx sobre a sua ideia acerca das Classes Sociais em três de suas obras: O Capital, O Manifesto comunista e o 18 de Brumário de Luís Bonaparte. Apesar de serem obras distintas, que mostram respectivamente três facetas de Karl Marx: teórico, político e histórico, as concepções de Classes nas três obras possuem pontos de encontro mapeáveis que possibilitam uma leitura peculiar sobre a sua visão do conceito, uma vez que este não foi desenvolvido em sua plenitude.

\section{ENTRE O TEÓRICO E O POLÍTICO}

Um primeiro ponto que merece destaque na abordagem acerca das classes sociais em Marx é tentar escapar da dicotomia do marxismo vulgar, que por vezes 
estabelece que duas classes antagônicas compõem a sociedade capitalista. Em diversos escritos são estabelecidas sim, dicotomias, que inclusive denunciam diversas ilusões existentes na sociedade como entre valor de uso e valor de troca, o duplo caráter do trabalho, a separação do Estado e Sociedade Civil, entre capitalistas e o proletariado. Entretanto, em nenhum momento Marx postula que essas duas classes estruturariam por si o sistema capitalista de produção. Há uma complexidade nessa colocação que precisa ser estabelecida.

Há evidentemente uma distinção entre os indivíduos capitalistas, donos dos meios de produção e proprietários das mercadorias produzidas em tal processo, e entre o grupo proletariado que desprovido dos meios de produção vende sua força de trabalho. Este, por sua vez se torna uma Mercadoria para sobreviver na sociedade capitalista, garantindo os subsídios necessários à sua existência e de suas famílias que também dependem da venda de sua força de trabalho, a classe proletária se sujeitará à diversas relações difíceis e opressoras dentro do sistema de produção. Isso possui um grande destaque onde Marx dedica boa parte de sua análise,

\footnotetext{
Para poder crescer e manter-se, um homem precisa consumir uma determinada quantidade de meios de subsistência; o homem, como a máquina, se gasta e tem que ser substituído por outro homem. Além da soma de artigos de primeira necessidade exigidos para o seu próprio sustento, ele precisa de outra quantidade dos mesmos artigos para criar determinado número de filhos, que hão de substituí-lo no mercado de trabalho e perpetuar a descendência dos trabalhadores (MARX, 1984. p. 99).
}

No Manifesto Comunista existe ainda uma certa dicotomia entre as classes, em especial pela classe proletária e a burguesia. Isso se deve, em minha análise, ao próprio posicionamento de Marx ao postular que o proletariado, ao passar por todos os malefícios presentes no sistema de produção capitalista, poderia ser o motor da mudança e engendrar a revolução que acabaria por findar o sistema de opressão que estrutura o sistema de produção. Ainda sobre a classe proletária, em meio a concorrência crescente da burguesia, Marx e Engels elencam que:

De todas as classes que ora enfrentam a burguesia, só o proletariado é uma classe verdadeiramente revolucionária. As outras classes degeneram e perecem com o desenvolvimento da grande indústria; o proletariado pelo contrário, é seu produto mais autêntico. As classes médias - pequenos 


\begin{abstract}
comerciantes, pequenos fabricantes, artesãos, camponeses - combatem o burguês porque este compromete sua existência como classes médias. Não são, pois, revolucionárias, mas conservadoras; mais ainda, reacionárias, pois pretendem fazer girar para trás a roda da História. Quando são revolucionárias é em consequência de sua iminente passagem para o proletariado; não defendem então seus interesses atuais, mas seus interesses futuros; abandonam seu próprio ponto de vista para se colocar no do proletariado (MARX, ENGELS, 2010. p. 49).
\end{abstract}

Nessa passagem é evidente a consideração de Marx e Engels acerca de diversas classes sociais que compõem a sociedade capitalista, anulando assim uma perspectiva puramente dicotômica, que desenvolveremos mais à frente quando falarmos sobre as classes sociais em $O 18$ de Brumário. Nesse sentido, o proletariado vai ser elencado como a classe social revolucionaria por excelência frente a luta contra a burguesia. Será a posição que ocupam no processo produtivo que desenvolverá toda a diferença, dominação e desigualdade entre os indivíduos exploradores e explorados. No início do Manifesto Comunista, Marx e Engels fazem uma breve análise que expõe a dicotomia entre dominados e dominantes:

Homem livre e escravo, patrício e plebeu, barão e servo, mestre de corporação e companheiro, numa palavra, opressores e oprimidos, em constante oposição, têm vivido numa guerra ininterrupta, ora franca, ora disfarçada; uma guerra que terminou sempre, ou por uma transformação revolucionária, da sociedade inteira, ou pela destruição das duas classes em luta (MARX, ENGELS, 2010. p. 40).

Os indivíduos que vendem a sua força de trabalho forçadamente para garantir a sua sobrevivência, portanto, essa força de trabalho será considerada por Marx como mera mercadoria no sistema de produção capitalista que mastiga toda essa classe de sujeitos que não tem outra opção a não ser vender sua força de trabalho, única coisa que possuem, uma vez destituídos dos meios de produção. Característica própria da sociedade moderna. “'Classe', assim, é definida em termos da relação de grupamentos individuais com osmeios de produção" (GIDDENS, 1975. p. 31). Em consonância ao debate proposto por Giddens, a partir de Marx e Engels torna-se evidente como a sociedade moderna se desenvolve a partir dos escombros da sociedade feudal, auxiliando ainda na reflexão de como se estruturam as classes na sociedade moderna e industrial, 


\begin{abstract}
A sociedade burguesa moderna, que brotou das ruínas da sociedade feudal, não aboliu os antagonismos de classe. Não fez senão substituir novas classes, novas condições de opressão, novas formas de luta às que existiram no passado. Entretanto, a nossa época, a época da burguesia, caracteriza-se por ter simplificado os antagonismos de classe. A sociedade divide-se cada vez mais em dois vastos campos opostos, em duas grandes classes diametralmente opostas: a burguesia e o proletariado (MARX, ENGELS, 2010. p. 41).
\end{abstract}

Sobre a questão da luta de classes, Marx se propõe a estabelecer diversos modelos para exemplificar o funcionamento do sistema capitalista de produção e a exploração do trabalho na qual este se baseia e como este sistema poderia ser superado. Os elencados anteriormente Manifesto Comunista e O Capital, possuíram objetivos distintos, contudo, as suas perspectivas sobre as classes sociais, como já foi destacado, conversam entre si.

Segundo a análise de Francis Wheen sobre a obra marxiana e em especial sobre o trabalho teórico desenvolvido na construção de $O$ Capital, é dito que: “ (...) em $\mathrm{O}$ Capital, a finalidade do autor consistiu em desvendar a lei econômica da sociedade burguesa ou, em diferente formulação, as leis do nascimento, desenvolvimento e morte do modo de produção capitalista" (WHEEN, 2007. p. 26). Será o caráter revolucionário da classe proletária que despertará tanto interesse em Marx, caráter revolucionário que é extremamente necessário para este autor na citada acima, morte do capitalismo.

O proprietário da força de trabalho é mortal. Se, portanto, sua aparição no mercado é para ser contínua, como pressupõe a contínua transformação de dinheiro em capital, então o vendedor da força de trabalho precisa perpetuarse "como todo indivíduo se perpetua pela procriação". As forças de trabalho subtraídas do mercado pelo desgaste e morte precisam ser continuamente substituídas ao menos por um número igual de novas forças de trabalho (MARX, 1984. p. 289).

O Manifesto por sua vez é uma obra de cunho político produzida no formato panfletário, que teve como objetivo expor para a classe proletária as possibilidades de emancipação que esta teria caso se unificasse e buscasse a revolução. A revolução levada a cabo pela classe trabalhadora unificada, acabaria por colocar um fim na sociedade de classes, uma vez que a própria concepção de uma sociedade de classes é, na visão de Marx e Engels, uma construção Burguesa. 
Isso só seria possível numa sociedade dita comunista, onde a própria concepção de Estado $^{3}$ fosse abolida. Isso não se daria de modo automático, o Estado e as suas funções ainda permaneceriam em voga após a revolução, ao passar pelo estágio Socialista haveria uma ditadura do proletariado como organizações de trabalhadores redistribuindo alimentos, bens, serviços e lucros de forma justa de acordo com a necessidade de cada sujeito. Só com a passagem posterior para o estágio comunista que a sociedade iria abolir o Estado e se uniria para o bem comum e coletivo numa sociedade sem classes (MARX, 2010).

Fiquemos com a reflexão da própria sociedade de classes como uma construção Burguesa e analisemos as classes que Marx elenca no 18 de Brumário de Luís Bonaparte e como certos estratos de classe acabam por dominar todo um coletivo de sujeitos. Destacando a própria burguesia, campesinato e lumpemproletariado na citada obra.

\section{A MULTIPLICIDADE DAS CLASSES NO CONTEXTO FRANCÊS:}

O 18 de Brumário de Luís Bonaparte explora um conjunto de episódios que culminaram no golpe de Luís Bonaparte na França. Não aceitando a explicação, comum entre os franceses, de que a nação foi surpreendida, ou que o golpe foi um ato de força de um único indivíduo. Marx indica que o golpe só foi possível devido às particularidades criadas pela luta de classes na França que terminaram por torná-lo um acontecimento inevitável. Demonstra, assim, com esse acontecimento empírico que os homens fazem sua história, mas não como a querem, não sob circunstâncias de sua própria escolha, mas sob as herdadas do passado (MARX, 2011).

Não cabendo aqui esboçar a multiplicidade dos acontecimentos que transcorrem entre 1848 a 1851, momento histórico analisado por Marx, exporemos alguns momentos que nos permitem acessar temas e categorias centrais ao pensamento marxiano. Sem dúvida a principal contribuição de $\mathrm{O} 18$ de Brumário advém da riqueza com que

\footnotetext{
${ }^{3}$ A função do Estado na teoria marxiana repousa em defender os interesses das classes dominantes por meio de seus instrumentos de regulação: sistema jurídico e o aparado militar e policial. No intuito de manter a ordem estabelecida, no caso da sociedade moderna, a dominação burguesa, o Estado desempenharia uma função de caráter repressivo capaz de manter o status quo. Ou seja, o Estado está estruturado, nas sociedades capitalistas, em função do capital. 
trabalha as noções de classe, das relações de classe, de Estado e da relação deste com as classes sociais, riqueza advinda do emprego do método dialético na análise dessas categorias. É justamente isso que faz com que O 18 de Brumário seja, não somente uma obra histórica que trata de um fato passado, mas uma importante referência para a compreensão de categorias e temas tão fundamentais do pensamento marxiano. Sobre a república burguesa de Luís Bonaparte, que possuiu o apoio de diversas classes existentes no contexto, Marx informa:

\begin{abstract}
A república burguesa triunfou. A seu lado alinhavam-se a aristocracia financeira, a burguesia industrial, a classe média, a pequena burguesia, o exército, o lúmpen proletariado organizado em Guarda Móvel, os intelectuais de prestígio, o clero e a população rural. Do lado do proletariado de Paris não havia senão ele próprio (MARX, 2011. p. 34-35).
\end{abstract}

Diante dos apontamentos já feitos sobre o 18 de Brumário e demais obras citadas neste artigo, elencaremos algumas das importantes contribuições deixadas por Marx. Essa obra desconstrói qualquer visão monolítica das classes sociais, uma vez que, mostra diversas classes sociais com interesses contraditórios no cenário francês. Demonstra, por exemplo, que a Burguesia não é uma classe homogênea ela se divide em diversas frações por exemplo a burguesia industrial, alta burguesia, pequena burguesia, apesar de distintas, essas classes têm em si uma perspectiva de conservação de privilégios dentro da sociedade, privilégios dos quais não vão abrir mão, "por esse vulgar egoísmo, enfim, que torna o burguês comum sempre pronto a sacrificar o interesse geral de sua classe por este ou aquele interesse particular" (MARX, 2011. p. 106).

Diante disto, tal classe não consegue formular um interesse geral, sacrificando seus interesses políticos por interesses particulares. O que coaduna com os argumentos de Marx e Engels no Manifesto Comunista ao colocar o proletariado como a classe revolucionária por excelência frente a burguesia, já que sofre com as dinâmicas capitalistas com mais força do que as demais classes citadas anteriormente, que acabam por deteriorar uma possível revolução. No caso do Manifesto, essa revolução ainda está no porvir, no caso analisado em 18 de Brumário a revolução, de 1848, já tinha acontecido e o autor conseguirá nesse mote fazer uma análise primorosa sobre as classes sociais em França. 
É importante que destaquemos a fragmentação das próprias classes destacadas por Marx, em especial a burguesia que se fragmenta em diversas e o campesinato, classe que foi de vital importância para os eventos narrados no 18 de brumário. Sobre o campesinato, Marx advoga que tal classe se fragmenta em diversas outras classes que viviam no campo, nos membros das classes campesinas se fundou o mito de que uma figura histórica chamada "Napoleão" traria para estes e sua glória passada, "Assim como os Bourbons representavam a grande propriedade territorial e os Orléans a dinastia do dinheiro, os Bonapartes são a dinastia dos camponeses, ou seja, da massa do povo francês" (MARX, 2011. p. 142). Contudo, o campesinato representado por Luís Bonaparte não era o camponês revolucionário, mas o camponês conservador.

\begin{abstract}
A dinastia de Bonaparte representa não o camponês revolucionário, mas o conservador; não o camponês que luta para escapar às condições de sua existência social, a pequena propriedade, mas antes o camponês que quer consolidar sua propriedade; não a população rural que, ligada à das cidades, quer derrubar a velha ordem de coisas por meio de seus próprios esforços, mas, pelo contrário, aqueles que, presos por essa velha ordem em um isolamento embrutecedor, querem ver-se a si próprios e suas propriedades salvos e beneficiados pelo fantasma do Império. Bonaparte representa não o esclarecimento, mas a superstição do camponês; não o seu bom-senso, mas o seu preconceito; não o seu futuro, mas o seu passado (MARX, 2011. p. 144).
\end{abstract}

Marx também demonstra com o caso Francês como a existência do lumpemproletariado ${ }^{4}$ pode representar um obstáculo à revolução proletária. Na medida em que o lumpen não participa dos meios de produção da sociedade, ele se vê privado de um elemento importante para a construção de uma visão de mundo comum, que inclua a consciência da necessidade de uma modificação qualitativa da sociedade.

\begin{abstract}
Marx refere-se ao lumpemproletariado, termo que traduz o alemão lumpenproletariat, como "o lixo de todas as classes", "uma massa desintegrada", que reunia "indivíduos arruinados e aventureiros egressos da burguesia, vagabundos, soldados desmobilizados, malfeitores recém-saídos da cadeia (...) batedores de carteira, rufiões, mendigos”, etc., nos quais Luís Bonaparte apoiou-se em sua luta pelo poder (BOTTOMORE, 1988. p. 354).
\end{abstract}

\footnotetext{
4 “O principal significado da expressão lumpemproletariado não está tanto na referência a qualquer grupo social específico que tenha papel social e político importante, mas antes no fato de ela chamar a atenção para o fato de que, em condições extremas de crise e de desintegração social em uma sociedade capitalista, grande número de pessoas podem separar-se de sua classe e vir a formar uma massa "desgovernada", particularmente vulnerável às ideologias e aos movimentos reacionários" (BOTTOMORE, 1988. p. 354).
} 
Essa ausência de uma consciência leva o lumpemproletariado a entrar no sistema de modo vil, servindo aos interesses da alta burguesia como sua massa de manobra, isso diferencia o lumpem da classe proletariada. É necessário que esta distinção seja trazida, já que Marx evidenciava a consciência de classe como algo acessível a classe proletária, é imprescindível que evidenciemos a diferença desta para o lumpemproletariado, diante das características elencadas acima.

Até aqui destacamos a multiplicidade de classes sociais que elenca Marx dentro de $O 18$ de Brumário de Luís Bonaparte, é através dessa obra, onde é colocado em uso o materialismo histórico, que destaca as classes sociais postas de modo não monolítico. Na produção marxiana já é possível elencar diversos elementos para uma análise de Classes densa, mesmo que seu conceito de classes sociais não tenha sido desenvolvido em plenitude no terceiro volume de $O$ Capital.

\section{CONCLUSÃO}

À guisa de uma conclusão, gostaria de revisitar alguns dos pontos destacados ao longo de minha panorâmica análise das ideias relacionadas as classes sociais dentro de três distintas obras produzidas por Marx e que são consideradas capitais para a compreensão de sua estrutura de pensamento. Diante do que foi posto neste artigo, gostaria de destacar que o uso de diferentes obras de Marx, no caso uma obra teórica, outra política e por fim um escrito histórico, não representam uma colocação de que o pensamento possa, de modo simplista, ser colocado em diferentes estruturas de pensamento diante da intencionalidade que seus escritos tiveram. Suas análises, em qualquer que seja o aspecto, possuem pontos de confluência, essa foi uma das questões abordadas nesta análise

Um desses pontos, certamente é a colocação da classe proletária como a única dotada das possibilidades de questionar a narrativa da alta burguesia e colocar em xeque o processo de dominação no sistema capitalista. Como foi dito ao longo do desenvolvimento deste artigo, outras classes também são oprimidas pela estrutura de dominação capitalista, contudo, apenas o proletariado seria dotado de uma possibilidade de desenvolver uma consciência de classe que torna viável um novo sistema. Esta 
colocaria a cabo a própria estrutura de classes, já que Marx advoga que essa estrutura é eminentemente burguesa, a luta de classes é nesse sentido, um ponto capital da teoria marxiana. As três obras utilizadas, trabalham essa questão do proletariado com suas respectivas particularidades. Contudo, ambas as obras dialogam para tornar mais visível o posicionamento político de Marx que penetra em toda a sua contribuição teórica, destacando com isso o diálogo promovido entre $O$ Capital e o Manifesto Comunista.

Com os elementos trazidos com o 18 de Brumário de Luís Bonaparte minha intenção foi direcionada a ver como Marx rompe de vez com as classes sociais sendo vistas de forma monolítica na sociedade capitalista. Várias classes sociais são elencadas ao longo da obra colocando à luz as suas respectivas relações com o momento histórico vivido na sociedade francesa. O interessante da contribuição marxiana é que dentro de uma classe social em particular, aqui tratamos de modo mais específico a burguesia e o campesinato, há uma fragmentação dentro dessa classe e múltiplos aspectos contribuem para isso. Por exemplo, a intencionalidade dos sujeitos e sua atuação política para conservar certos privilégios dentro da dominação exercida. Esse aspecto da intencionalidade será ricamente desenvolvido por autores e autoras de vertente marxista nos anos que sucedem as publicações marxianas.

O artigo aqui desenvolvido representa um esforço teórico de apropriação das ideias marxianas acerca das classes sociais e uma tentativa de mostrar como a abordagem em obras de cunho distinto revelam uma intenção pungente do autor em contribuir para uma sociedade mais igualitária, com possibilidade de mudanças efetivas para as classes exploradas pelo regime, isso passa pelo Marx teórico, político e também pelo Marx histórico.

\section{BIBLIOGRAFIA}

BOTTOMORE, T. (Org.). Dicionário do pensamento marxista. Rio de Janeiro: Jorge Zahar, 1988.

GIDDENS, A. A estrutura de classes das sociedades avançadas. Rio de Janeiro: Zahar, 1975.

MARX, K. O Capital: crítica da economia política. São Paulo: DIFEL, 1984.

MARX, K. O 18 de Brumário de Luís Bonaparte. São Paulo: Boitempo, 2011. 
MARX, K. e ENGELS, F. Manifesto Comunista. São Paulo: Boitempo, 2010.

WHEEN, F. “O Capital” de Marx: uma biografia. (Tradução de Sérgio Lopes). Rio de Janeiro: Jorge Zahar, 2007. 